\title{
Automatic Air Volume Control System for Ventilation of Two Patients Using a Single Ventilator: A Large Animal Model Study
}

Krzysztof Zielinski ( $\sim$ kzielinski@ibib.waw.pl )

Nalecz Institute of Biocybernetics and Biomedical Engineering, Polish Academy of Sciences

Barbara Lisowska

Department of Anesthesiology and Intensive Medical Care, National Geriatrics, Rheumatology and Rehabilitation Institute

Katarzyna Siewruk

Warsaw University of Life Sciences - SGGW, Veterinary Research Center, Center for Biomedical Research and Research Center for Regenerative Medicine

Maria Sady

Warsaw University of Life Sciences - SGGW, Veterinary Research Center, Center for Biomedical Research and Research Center for Regenerative Medicine

Karolina Ferenc

Warsaw University of Life Sciences - SGGW, Veterinary Research Center, Center for Biomedical Research and Research Center for Regenerative Medicine

Maciej Barwijuk

I Department of Anaesthesiology and Intensive Care, Medical University of Warsaw

Jaroslaw Olszewski

Warsaw University of Life Sciences - SGGW, Veterinary Research Center, Center for Biomedical Research and Research Center for Regenerative Medicine

\section{Krzysztof Anusz}

Warsaw University of Life Sciences - SGGW, Veterinary Research Center, Center for Biomedical Research and Research Center for Regenerative Medicine Artur Jablonski

Warsaw University of Life Sciences - SGGW, Veterinary Research Center, Center for Biomedical Research and Research Center for Regenerative Medicine Magdalena Gajewska

Warsaw University of Life Sciences - SGGW, Veterinary Research Center, Center for Biomedical Research and Research Center for Regenerative Medicine

Piotr Okrzeja

Nalecz Institute of Biocybernetics and Biomedical Engineering, Polish Academy of Sciences

Marcin Michnikowski

Nalecz Institute of Biocybernetics and Biomedical Engineering, Polish Academy of Sciences

Dorota Pijanowska

Nalecz Institute of Biocybernetics and Biomedical Engineering, Polish Academy of Sciences

Krzysztof Pluta

Nalecz Institute of Biocybernetics and Biomedical Engineering, Polish Academy of Sciences

Elzbieta Remiszewska

Nalecz Institute of Biocybernetics and Biomedical Engineering, Polish Academy of Sciences

Marek Darowski

Nalecz Institute of Biocybernetics and Biomedical Engineering, Polish Academy of Sciences

Romuald Zabielski

Warsaw University of Life Sciences - SGGW, Veterinary Research Center, Center for Biomedical Research and Research Center for Regenerative Medicine

Adam Liebert

Nalecz Institute of Biocybernetics and Biomedical Engineering, Polish Academy of Sciences

Katarzyna Kramek-Romanowska

Faculty of Chemical and Process Engineering Warsaw University of Technology

Anna Stecka

Nalecz Institute of Biocybernetics and Biomedical Engineering, Polish Academy of Sciences

Maciej Kozarski

Nalecz Institute of Biocybernetics and Biomedical Engineering, Polish Academy of Sciences

Raman Pasledni

Nalecz Institute of Biocybernetics and Biomedical Engineering, Polish Academy of Sciences

\section{Zdzislaw Gajewski}

Warsaw University of Life Sciences - SGGW, Veterinary Research Center, Center for Biomedical Research and Research Center for Regenerative Medicine

\section{Piotr Ladyzynski}

Nalecz Institute of Biocybernetics and Biomedical Engineering, Polish Academy of Sciences 
Keywords: volume, ventilation, patients, COVID-19

Posted Date: December 13th, 2021

DOI: https://doi.org/10.21203/rs.3.rs-1112029/v1

License: (c) (i) This work is licensed under a Creative Commons Attribution 4.0 International License. Read Full License 


\section{Abstract}

The COVID-19 pandemic outbreak led to a global ventilator shortage. Hence, different strategies to use a single ventilator to support multiple patients are considered. A mechatronic system Ventil divides and automatically controls gas volume pumped through two channels and was successfully validated in independent lung ventilation. We used Ventil in a series of experiments on a large animal model to verify its usability for ventilation in two patients using a single ventilator. The results of investigations on 12 pigs showed that the physiological level of respiratory parameters was maintained for 24 hours. Application of Ventil did not lead to injuries in the lungs, as indicated by CT scan analysis. We conclude that ventilation using Ventil can be considered safe in patients subjected to deep sedation without spontaneous breathing efforts.

\section{Introduction}

In the last year, clinical centers around the world struggled with an extraordinary shortage of resources related to the outbreak of COVID-19 (1). The spectacular example was the Lombardian case in Italy, where in February 2020, after the initial COVID-19 outbreak, clinicians reported a serious shortage of ventilators (2). In a large number of cases, COVID-19 undergoes atypical acute respiratory distress syndrome (ARDS) (3), which leads to the necessity of mechanical ventilation. Thus, a global-scale problem of ventilator shortages is related to the increase in the number of people requiring long-term ventilatory therapy, which could currently exceed the number of ventilators available in some hospitals.

The most dramatic but necessary approach to address ventilator shortages is triage (4). To address the shortage of ventilators, it was proposed to design simple (even 3D printed) and inexpensive ventilators, which may allow starting a large-scale production of respiration support systems in a short time (5). However, these devices are typically not certified for clinical use and suffer from limited durability and disability to control the mechanical ventilation process for long periods. In several reports published some years ago, anesthesiologists considered solving the problem of a lack of ventilators by sharing a single ventilator for simultaneous therapy of two or even four patients (6-8). The proposed techniques usually come down to the use of the standard tubing and ventilatory circuit parts with a straightforward means to divide an inspiratory gas flow between patients. However, this approach was criticized as not satisfactory to stabilize the ventilation of each patient in the event of changes in lung mechanics in any of the ventilated patients (9).

Recently, various configurations of ventilator sharing systems have been proposed and tested (10-12). These systems provide varying degrees of control over ventilatory branches, providing airflow to the patients. In most of these solutions, manually titrated pneumatic valves are used. These concepts should only be considered a last resort solution, which can be used only in emergency situations. It was reported by several groups that the regulation of inspiratory flow to each connected patient using manually titrated valves requires a constant presence of medical staff at a patient bed. However, this increased patient monitoring effort still does not guarantee safe, multiplexing ventilation. The risk related to such a ventilatory strategy is relatively high; however, it can be considered a potential bridge to full ventilatory support of the patient $(6,11,13-18)$.

Another clinical problem of shared ventilation is the risk of transmission of pathogens in the respiratory tracts. Then, a research problem arises, resulting from a lack of fully defined methods that can be used to assess the transport of pathogens in the ventilation duct under laboratory conditions in a short time, not undertaking the risk of biohazards. For pathogens such as viruses, the term "viral load", expressed as titer, is a numerical representation of the quantity of virus in a given volume of fluid in a sample, e.g., saliva, blood, plasma, etc. For viruses transmitted via airborne droplets, the most common method for viral titer estimation is quantitative $P C R(q P C R)$ performed on nasopharyngeal swab samples. Despite the large body of evidence concerning SARS-CoV-2, SARSCOV, and MERS-COV viral load dynamics, duration of viral shedding, and infectiousness (19) published to date, there are few or no data on the virus load required for human infection. Nonetheless, Han et al. showed that the average titre of initial viral load obtained from swab specimens taken from asymptomatic children was ca. $2 \times 10^{6}$ genomic $R N A$ copies per $\mathrm{mL}$, whereas symptomatic children had an initial viral load as high as $1 \times 10^{9}(20)$.

Moreover, according to Chu et al., in the culture medium of Caco2 and Calu3 cells infected with SARS-CoV-2 virus, the number of virus genome copies $120 \mathrm{~h}$ after infection was determined to be $10^{9}$ in $1 \mathrm{~mL}$ of supernatant (21). The multiplicity of infection (MOI) was 0.1 . In our studies using the viral phantom in the form of fluorescently labeled nanospheres, the estimated phantom titer was determined from an exponential pattern of viral reproduction in the respiratory system. Another published study showed that the minimal dose of MERS-CoV required to infect cell culture effectively was $10^{7}$ copies per $\mathrm{mL}$ (22). In the case of SARS-CoV-2, no infection occurred with a titre below $10^{6}$ copies per $\mathrm{mL}$ (23), cycle threshold values higher than 24 in another study (24) or higher than 34 in other studies $(25,26)$.

We validated the concept of mechanical ventilation in two patients with one ventilator based on continuous automatic control of tidal volume division between ventilated subjects (27). During long-term multiplex ventilation, only such a solution ensures that the ventilation of each patient is stabilized, regardless of how dynamically lung compliance or airway resistance changes. This technical approach is based on previous studies in which we proposed control of tidal volume division between two lungs of a ventilated patient using one ventilator and a double-lumen tube. This independent lung ventilation technology was validated in a series of technical experiments $(28,29)$ and clinical tests carried out in patients ventilated during thoracic surgeries $(30)$ or undergoing differential ventilation therapy in an intensive care unit (31). A medical device called Ventil, based on these previous studies, was developed and certified for independent ventilation of two lungs in a single patient (manufacturer Łukasiewicz-ITAM, Zabrze, Poland). This device technically allows two patients to be ventilated with one ventilator. The usability of the Ventil device in this application was evaluated in long-term large animal model ventilation experiments.

The splitting ventilation approach carries the risk of mechanical ventilation alterations in one patient when the respiratory mechanics in the second patient change (respiratory deterioration or improvement). Therefore, supplementary to animal experiments, laboratory tests using Ventil were performed, assessing to what extent pressure and flow delivered to one ventilated object are altered in a case of changing mechanical properties (resistance and compliance) of the 
second ventilated object. Additionally, a pathogen transmission test was performed. For the investigation of spreading of pathogens along the respiratory tract and contamination of the second tract, fluorescent nanospheres were used as a phantom of virus particles.

\section{Results}

\section{Animal experiments}

We investigated 16 pigs in 8 pairs ventilated by the Ventil device and a ventilator or an anesthetic machine (Fig. 1A) set to volume-controlled ventilation modes. One experiment (one pair of pigs) was abandoned after 4 hours due to decreasing saturation in both animals and cardiorespiratory disorders. Asystole was found in one pig along with resistance to administered drugs. In addition, dysfunction of unidirectional mechanical positive end-expiratory pressure (PEEP) components in the circuit was found. Another experiment was aborted after approximately 8-9 hours due to carbon dioxide accumulation, and the body temperature increased up to $43^{\circ} \mathrm{C}$ in one pig. The animal died as a result of asystole. Malignant hyperthermia was considered the cause of death. These experiments were excluded from analyses. The configuration of the other 6 successfully finished experiments is summarized in Fig. 1B and in Table 1.

Table 1

Animal experiments results. Median and interquartile range values for selected ventilatory parameters for ventilated pairs. $T V$, tidal volume; $R R$, respiratory rate; FiO2, oxygen fraction in the inhaled gas; $\mathrm{SpO}$, arterial blood saturation; EtCO2, end-tidal carbon dioxide; $P I P$, peak inspiratory pressure; $P E E P i$, intrinsic positive end-expiratory pressure; $\triangle P$, driving pressure; $C s t$, static lung compliance; $I Q R$, interquartile range;

\begin{tabular}{|c|c|c|c|c|c|c|c|c|c|c|c|c|c|}
\hline \multirow{2}{*}{$\begin{array}{l}\text { Pair no } \\
\text { Pig no }\end{array}$} & & \multicolumn{2}{|l|}{1} & \multicolumn{2}{|l|}{2} & \multicolumn{2}{|l|}{3} & \multicolumn{2}{|l|}{4} & \multicolumn{2}{|l|}{5} & \multicolumn{2}{|l|}{6} \\
\hline & & \#1 & \#2 & $\# 1$ & $\# 2$ & $\# 1$ & \#2 & \#1 & \#2 & $\# 1$ & \#2 & \#1 & \#2 \\
\hline Variable & Unit & $\begin{array}{l}\text { Median } \\
\text { (Iqr) }\end{array}$ & $\begin{array}{l}\text { Median } \\
\text { (lqr) }\end{array}$ & $\begin{array}{l}\text { Median } \\
\text { (Iqr) }\end{array}$ & $\begin{array}{l}\text { Median } \\
\text { (lqr) }\end{array}$ & $\begin{array}{l}\text { Median } \\
\text { (Iqr) }\end{array}$ & $\begin{array}{l}\text { Median } \\
\text { (Iqr) }\end{array}$ & $\begin{array}{l}\text { Median } \\
\text { (Iqr) }\end{array}$ & $\begin{array}{l}\text { Median } \\
\text { (Iqr) }\end{array}$ & $\begin{array}{l}\text { Median } \\
\text { (Iqr) }\end{array}$ & $\begin{array}{l}\text { Median } \\
\text { (Iqr) }\end{array}$ & $\begin{array}{l}\text { Median } \\
\text { (Iqr) }\end{array}$ & $\begin{array}{l}\text { Median } \\
\text { (lqr) }\end{array}$ \\
\hline \multirow[t]{2}{*}{ TV } & $\mathrm{ml} / \mathrm{kg}$ & 4.15 & 4.98 & 4.96 & 4.88 & 7.17 & 7.05 & $\div$ & 5.58 & 6.79 & 5.52 & 5.83 & 6.96 \\
\hline & & $\begin{array}{l}(4.49 \div \\
3.73)\end{array}$ & $\begin{array}{l}(5.39 \div \\
4.37)\end{array}$ & $\begin{array}{l}(5.19 \div \\
4.80)\end{array}$ & $\begin{array}{l}(5.08 \div \\
4.75)\end{array}$ & $\begin{array}{l}(7.29 \div \\
7.06)\end{array}$ & $\begin{array}{l}(7.20 \div \\
6.93)\end{array}$ & & $\begin{array}{l}(5.68 \div \\
5.51)\end{array}$ & $\begin{array}{l}(7.14 \div \\
6.40)\end{array}$ & $\begin{array}{l}(5.78 \div \\
5.08)\end{array}$ & $\begin{array}{l}(6.04 \div \\
5.70)\end{array}$ & $\begin{array}{l}(7.09 \div \\
6.82)\end{array}$ \\
\hline \multirow[t]{2}{*}{ RR } & $1 / \min$ & 28 & 28 & 24 & 24 & 22 & 24 & $25^{\star \star}$ & 25 & 27 & 27 & 21 & 21 \\
\hline & & $\begin{array}{l}(28 \div \\
26)\end{array}$ & $\begin{array}{l}(28 \div \\
25)\end{array}$ & $\begin{array}{l}(24 \div \\
24)\end{array}$ & $\begin{array}{l}(24 \div \\
24)\end{array}$ & $\begin{array}{l}(24 \div \\
22)\end{array}$ & $\begin{array}{l}(24 \div \\
22)\end{array}$ & $\frac{(26 \div}{25)}$ & $\frac{(26 \div}{25)}$ & $\begin{array}{l}(27 \div \\
26)\end{array}$ & $\begin{array}{l}(27 \div \\
26)\end{array}$ & $\frac{(22}{20)} \div$ & $\frac{(22}{20)} \div$ \\
\hline \multirow[t]{2}{*}{$\mathrm{FiO} 2$} & $\%$ & 44 & 44 & 40 & 40 & 53 & 54 & $29 \star \star$ & 29 & 48 & 49 & 35 & 34 \\
\hline & & $\begin{array}{l}(52 \div \\
42)\end{array}$ & $\begin{array}{l}(51 \div \\
42)\end{array}$ & $\begin{array}{l}(40 \div \div \\
35)\end{array}$ & $\begin{array}{l}(40 \div \\
35)\end{array}$ & $\begin{array}{l}(54 \div \\
44)\end{array}$ & $\begin{array}{l}(54 \div \\
44)\end{array}$ & $\begin{array}{l}(44 \div \\
29)\end{array}$ & $\begin{array}{l}(44 \div \\
29)\end{array}$ & $\begin{array}{l}(61 \div \\
44)\end{array}$ & $\begin{array}{l}(51 \div \\
44)\end{array}$ & $\begin{array}{l}(45 \div \\
34)\end{array}$ & $\begin{array}{l}(44 \div \\
33)\end{array}$ \\
\hline \multirow[t]{2}{*}{ SpO2 } & $\%$ & 96 & 96 & 95 & 94 & 96 & 100 & 100 & 95 & 97 & 94 & 95 & 94 \\
\hline & & $\begin{array}{l}(97 \div \\
94.7)\end{array}$ & $\begin{array}{l}(97.5 \div \\
95.5)\end{array}$ & $\begin{array}{l}(96.8 \div \\
90.4)\end{array}$ & $\begin{array}{l}(95.4 \div \\
91.9)\end{array}$ & $\begin{array}{l}(98.1 \div \\
94.8)\end{array}$ & $\begin{array}{l}(100 \div \\
97.5)\end{array}$ & $\begin{array}{l}(100 \div \\
99.4)\end{array}$ & $\begin{array}{l}(96 \div \\
94.3)\end{array}$ & $\begin{array}{l}(98.2 \div \\
96.8)\end{array}$ & $\begin{array}{l}(96.7 \div \\
92.1)\end{array}$ & $\begin{array}{l}(96.2 \div \\
93.5)\end{array}$ & $\begin{array}{l}(95.2 \div \\
93.6)\end{array}$ \\
\hline \multirow[t]{2}{*}{$\mathrm{EtCO} 2$} & $\mathrm{mmHg}$ & 53.2 & 65.6 & 54.4 & 45.4 & 51.5 & 47.8 & $\div$ & 49.0 & 50.2 & 42.6 & 52.9 & 49.9 \\
\hline & & $\begin{array}{l}(61 \div \\
49.7)\end{array}$ & $\begin{array}{l}(81 \div \\
55.9)\end{array}$ & $\begin{array}{l}(57 \div \\
52.3)\end{array}$ & $\begin{array}{l}(49.8 \div \\
43.4)\end{array}$ & $\begin{array}{l}(53.7 \div \\
49.3)\end{array}$ & $\begin{array}{l}(49 \div \\
46.6)\end{array}$ & & $\begin{array}{l}(50.6 \div \\
48)\end{array}$ & $\begin{array}{l}(52.1 \div \\
46.7)\end{array}$ & $\begin{array}{l}(45.2 \div \\
39.3)\end{array}$ & $\begin{array}{l}(54.7 \div \\
49.7)\end{array}$ & $\begin{array}{l}(57.2 \div \\
48.5)\end{array}$ \\
\hline \multirow[t]{2}{*}{ PIP } & $\mathrm{cmH} 2 \mathrm{O}$ & 17.4 & 17.60 & 17.9 & 18.9 & 24.0 & 21.0 & $\div$ & 17.6 & 29.1 & 20.1 & 18.4 & 18.5 \\
\hline & & $\begin{array}{l}(19.4 \div \\
15.8)\end{array}$ & $\begin{array}{l}(18.9 \div \\
16.3)\end{array}$ & $\begin{array}{l}(18.3 \div \\
17.3)\end{array}$ & $\begin{array}{l}(19.6 \div \\
17.7)\end{array}$ & $\begin{array}{l}(27 \div \\
20.9)\end{array}$ & $\begin{array}{l}(22.4 \div \\
18.7)\end{array}$ & & $\begin{array}{l}(18.1 \div \\
17.1)\end{array}$ & $\begin{array}{l}(33.1 \div \\
26)\end{array}$ & $\begin{array}{l}(21 \div \\
18.9)\end{array}$ & $\begin{array}{l}(18.9 \div \\
17.9)\end{array}$ & $\begin{array}{l}(18.8 \div \\
18.1)\end{array}$ \\
\hline \multirow[t]{2}{*}{ PEEPi } & $\mathrm{cmH} 2 \mathrm{O}$ & 12.1 & 12.6 & 12.2 & 12.1 & 10 & 9 & $\div$ & 9 & 11.5 & 13.3 & 8.9 & 9 \\
\hline & & $\begin{array}{l}(13.1 \div \\
8.6)\end{array}$ & $\begin{array}{l}(13.2 \div \\
11.6)\end{array}$ & $\begin{array}{l}(13.2 \div \\
11.3)\end{array}$ & $\begin{array}{l}(12.9 \div \\
11.3)\end{array}$ & $\begin{array}{l}(10.6 \div \\
9.4)\end{array}$ & $\begin{array}{l}(9.7 \div \\
8.4)\end{array}$ & & $\begin{array}{l}(9.7 \div \\
8.7)\end{array}$ & $\begin{array}{l}(12.5 \div \\
9.6)\end{array}$ & $\begin{array}{l}(13.8 \div \\
12.6)\end{array}$ & $\begin{array}{l}(10 \div \\
8.2)\end{array}$ & $\begin{array}{l}(9.7 \div \\
8.3)\end{array}$ \\
\hline \multirow[t]{2}{*}{$\Delta \mathrm{P}$} & $\mathrm{cmH} 2 \mathrm{O}$ & 4.1 & 4.2 & 2.5 & 3.3 & 12 & 8.3 & $\div$ & 6.1 & 10.6 & 3.7 & 6.8 & 7 \\
\hline & & $\begin{array}{l}(8.4 \div \\
-3.1)^{\star}\end{array}$ & $\begin{array}{l}(7.2 \div \\
-1.4)^{\star}\end{array}$ & $\begin{array}{l}(3.4 \div \\
1.6)\end{array}$ & $\begin{array}{l}(4.4 \div \\
1.6)\end{array}$ & $\begin{array}{l}(13.7 \div \\
9.2)\end{array}$ & $\begin{array}{l}(9.3 \div \\
7.4)\end{array}$ & & $\begin{array}{l}(6.7 \div \\
5.4)\end{array}$ & $\begin{array}{l}(14.5 \div \\
9.5)\end{array}$ & $\begin{array}{l}(4.3 \div \\
3)\end{array}$ & $\begin{array}{l}(7.4 \div \\
6.2)\end{array}$ & $\begin{array}{l}(7.7 \div \\
6.4)\end{array}$ \\
\hline \multirow[t]{2}{*}{ Cst } & $\mathrm{ml} / \mathrm{cmH} 2 \mathrm{O}$ & 36.07 & 48.50 & 143.52 & 89.65 & 37.88 & 52.11 & $\div$ & 60.77 & 25.27 & 108.53 & 81.14 & 63.85 \\
\hline & & $\begin{array}{l}(56.3 \div \\
-62.1)^{\star}\end{array}$ & $\begin{array}{l}(86.4 \div \\
-51.9)^{\star}\end{array}$ & $\begin{array}{l}(196 \div \\
86.9)\end{array}$ & $\begin{array}{l}(116.9 \\
\div 44.5)\end{array}$ & $\begin{array}{l}(49.2 \div \\
33.1)\end{array}$ & $\begin{array}{l}(57.4 \div \\
47.3)\end{array}$ & & $\begin{array}{l}(67.1 \div \\
55.5)\end{array}$ & $\begin{array}{l}(28 \div \\
16.6)\end{array}$ & $\begin{array}{l}(136.2 \\
\div 93.2)\end{array}$ & $\begin{array}{l}(90.6 \div \\
73.5)\end{array}$ & $\begin{array}{l}(69.3 \div \\
59.3)\end{array}$ \\
\hline
\end{tabular}

The median SpO2 for all animals was approximately $95 \%$ or more, which is higher than the considered safe level ( $90 \%)$. The median oxygen fractions, in most cases, were below the toxicity level $($ FiO2 < 0.5). The median EtCO2 level was above the normal range $(35-45$ mmHg); thus, permissive hypercapnia was maintained in the experiments. Driving pressure is the factor most responsible for lung injury. In $A R D S$, it is considered to be $<14 \mathrm{cmH} 20$. The median $\triangle P$ was 
below $10 \mathrm{cmH} 20$ for all except 2 cases: experiment 5, pig \#1 with chronic emphysema and pneumothorax of the left lung and pig \#1 in experiment 3 with reduced compliance caused by $200 \mathrm{ml}$ of saline in the lungs. These two pigs are characterized by lower (median) static lung compliance than the others. They also have the highest PIP values. Median TVs (expressed in $\mathrm{ml} \mathrm{per} \mathrm{kg}$ ) were in the range of $\sim 4.0-7.5$ for all pigs, close to the defined range of 4-6 $\mathrm{ml} / \mathrm{kg}$ recommended for mechanical ventilation in ARDS subjects.

We performed computer tomography $(C T)$ of the thorax immediately before and after the experiment for all pigs. We investigated $C T$ scans in terms of the presence of emphysema, pneumothorax and pleural effusion. Concerning emphysema, we did not find it in any subject before and after ventilation, except subject \#1 (experiment 5), where right-side emphysema was indicated before and after the experiment. Concerning pneumothorax, we did not find pneumothorax in any subject before and after ventilation, except the same animal that presented signs of emphysema, where left-side pneumothorax was indicated before and both-side pneumothorax after the experiment. Concerning pleural effusion, we did not find it in any subject before the experiment and only trace amounts on both sides in subject \#2 (experiment 1) after ventilation.

The analysis of $C T$ scans showed that generally, the Ventil together with a ventilator or anesthetic machines did not cause any severe lung injuries in ventilated animals, with one exception - subject \#1 in experiment 5 , which was characterized by chronic emphysema and pneumothorax before the experiment and then - very low lung compliance. This animal had the highest median $P I P$ value and $\Delta P$ value over $10 \mathrm{cmH} 20$.

\section{Time-trend analysis of the selected animal experiments}

In Fig. 2A-B, we present the time trends of the experiments conducted on a pair in experiment 6 . The animals were connected to a single ventilator through a Ventil device and were ventilated for approximately 24 hours. We adjusted tidal volume, RR, maximal flow (Vmax), FiO2, inspiratory to expiratory ratio (I:E) in the ventilator and the Ventil division knob to keep animal respiratory variables in the physiological range. In time trends, we marked $m 1-m 4$ symbols indicating exemplary events related to the experiment. Marker $m 1$ indicates the time when the Ventil flow division ratio was significantly changed to decrease $E t C O 2$ in object \#2 and increase it in object \#1. Marker $m 2$ indicates the time when $R R$ and FiO2 were decreased. Marker $m 3$ indicates the time when the side on which pigs were lying was changed. Before this, we found a rapid increase in $P I P$ and then $\triangle P$ and a reduction in intrinsic $P E E P$ and the static compliance Cst of object \#1. The body temperature of this pig tended to be distinctly elevated on the side it was lying on during all the experiments. This temperature elevation probably accompanied the Cst decrease, as these rapid Cst changes disappeared after the body position was changed. Therefore, next, the repositioning of this pig was done every 2 hours, not 4 hours, as for other pigs. The rapid decrease in Cst on \#1 did not cause significant changes in the ventilation of object \#2. Marker $m 4$ shows the moment pig \#1 was disconnected, and a 2 liter respiratory bag was terminated to the breathing circuit. This resulted in a tidal volume increase for pig \#2, which was followed by an increase in PIP and a decrease in EtCO2. This phenomenon we also found in a second experiment, described in the next paragraph.

In experiment 3 , in the 2 nd and 8 th hours of the experiment, we introduced bronchopulmonary $100 \mathrm{ml}$ of saline (in total $200 \mathrm{ml}$ ) to pig \#1 to induce changes in lung parameters mimicking ARDS. The goal was to assess the influence of deterioration of mechanical properties of the lungs/respiratory track in one subject on ventilatory variables of the second subject. The time trends of this experiment are presented in Fig. $2 \mathrm{C}$. Marker S1 indicates the injection of the first $100 \mathrm{ml}$ of saline to pig \#1 lungs. It caused a gradual increase in PIP in pig \#1, while in pig \#2, ventilatory parameters were not changed significantly. Marker $p 1$ indicates the time when ventilatory parameters were changed. Markers $p 2$ and $p 3$ indicate the time periods when a 2 -liter respiratory bag was connected instead of pigs \#1 and \#2, respectively. Marker S2 indicates the injection of the second $100 \mathrm{ml}$ portion of saline to pig \#1. It caused the next gradual increase in PIP in this object. However, it virtually did not affect the ventilation of pig \#2. Marker $p 4$ is the time when the side on which pigs were lying was changed from right to left. Marker $p 5$ indicates disconnection of pig \#1 and connection of the 2-liter respiratory bag into the breathing circuit.

\section{Arterial Blood Gas analysis in animal experiments}

The pairs of pigs (Fig. 1B) were divided into two groups in terms of weight: the WS group included pigs with equal or similar weights, and the WD group included pigs with different weights. We examined arterial blood gas $(A B G)$ parameters. The results are presented in Fig. 3.

The comparison of all $A B G$ samples in the $W S$ and $W D$ groups showed that statistically significant differences between groups were found in relation to $p H$, pO2, and $\mathrm{SaO} 2$ (Table 2). The presented results show the connection between those parameters according to the well-known acid-base equilibrium model, and there is confirmation of the reliability and validity of the research approach. The observations concerning steady changes in time of $A G B$ parameters in groups WS and WD showed that there was no statistically significant difference between the values of these parameters across the time (independent variable) - Table 2. Despite the lack of these statistically significant differences, in the WD group, Be(ecf) showed a positive value of the Spearman correlation coefficient $(r=0.433)$, which means that the $B e(e c f)$ values increased over time during the experiments. In relation to the WS group, the values of the Spearman correlation coefficients were also positive for $\mathrm{CHCO}^{-}$and $\mathrm{Be}(\mathrm{ecf})(0.509$ and 0.561 , respectively). In the WS group, the opposite trend was found for lactate levels $(r=-0.393)$, which means that lactate values decreased over time. 
Table 2

Arterial blood gas analysis from animal experiments. Summary for two animal groups $\div$ pairs with similar weight (WS) and pairs with different weight $(W D)$. Mann $\div$ Whitney U Test - between the groups for all blood samples. Friedman Test - Analysis of blood samples across time by the ANOVA Friedman test for each group separately. $p H$, the activity of hydrogen ions; $p C O 2$, carbon dioxide partial pressure; $\mathrm{pO} 2$, oxygen partial pressure; $\mathrm{CHCO}^{\div}$, bicarbonate concentration; $\mathrm{Be}$ (ecf), base excess in the extracellular fluid; SaO2, oxygen saturation of hemoglobin, lactate, lactate level; IQR, interquartile range; $W$, Kendal's coefficient of concordance; $r$, Spearman's rank correlation coefficient:

\begin{tabular}{|c|c|c|c|c|c|c|c|c|c|c|}
\hline \multicolumn{5}{|c|}{ Mann $\div$ Whitney U Test } & \multirow{2}{*}{\multicolumn{3}{|c|}{$\begin{array}{c}\text { WS } \\
\text { Friedman Test }\end{array}$}} & \multirow{2}{*}{\multicolumn{3}{|c|}{$\begin{array}{c}\text { WD } \\
\text { Friedman Test }\end{array}$}} \\
\hline \multirow[b]{2}{*}{ Variable } & \multirow[b]{2}{*}{ Unit } & \multirow{2}{*}{$\begin{array}{l}\text { WS }(\mathrm{n}=31 \#) \\
\text { Median [IQR] }\end{array}$} & \multicolumn{2}{|l|}{ WD $(n=29)$} & & & & & & \\
\hline & & & Median [IQR] & $p$ & $p$ & $w$ & $r$ & $p$ & $w$ & $r$ \\
\hline \multirow[t]{2}{*}{$\mathrm{pH}$} & & 7.39 & 7.42 & $.023^{*}$ & .760 & 0.155 & 0.075 & .554 & 0.156 & 0.215 \\
\hline & & {$[7.35 \div 7.43]$} & {$[7.41 \div 7.44]$} & & & & & & & \\
\hline \multirow[t]{2}{*}{$\mathrm{pCO} 2$} & $\mathrm{mmHg}$ & 54.8 & 52.7 & .169 & .371 & 0.355 & 0.164 & .661 & 0.120 & $\div 0.126$ \\
\hline & & {$[49.8 \div 60.5]$} & {$[48.7 \div 54.2]$} & & & & & & & \\
\hline \multirow[t]{2}{*}{ p02 } & $\mathrm{mmHg}$ & 195.4 & 169.6 & $.007 *$ & .139 & 0.578 & $\div 0.341$ & .451 & 0.184 & $\div 0.028$ \\
\hline & & {$[184.6 \div 203.9]$} & {$[147.3 \div 192.9]$} & & & & & & & \\
\hline \multirow[t]{2}{*}{$\mathrm{CHCO} 3 \div$} & $\mathrm{mmol} / \mathrm{L}$ & 33.1 & 33.7 & .395 & .057 & 0.763 & 0.509 & .142 & 0.344 & 0.324 \\
\hline & & {$[31.6 \div 35.0]$} & {$[32.8 \div 35.1]$} & & & & & & & \\
\hline \multirow[t]{2}{*}{$\mathrm{Be}(\mathrm{ecf})$} & $\mathrm{mmol} / \mathrm{L}$ & 8.3 & 9.4 & .184 & .082 & 0.689 & 0.561 & .237 & 0.277 & 0.433 \\
\hline & & {$[6.9 \div 10.1]$} & {$[7.9 \div 10.8]$} & & & & & & & \\
\hline \multirow[t]{2}{*}{$\mathrm{SaO} 2$} & $\%$ & 99.7 & 99.4 & $<.001^{*}$ & .318 & 0.393 & $\div 0.137$ & .294 & 0.247 & $\div 0.052$ \\
\hline & & {$[99.6 \div 99.7]$} & {$[98.6 \div 99.6]$} & & & & & & & \\
\hline \multirow[t]{2}{*}{ Lactate } & $\mathrm{mmol} / \mathrm{L}$ & 0.70 & 0.71 & .947 & .339 & 0.378 & $\div 0.393$ & .634 & 0.128 & $\div 0.184$ \\
\hline & & {$[0.51 \div 0.92]$} & {$[0.46 \div 0.95]$} & & & & & & & \\
\hline \multicolumn{11}{|c|}{ * $p<0.05$ considered statistically significant } \\
\hline \multicolumn{11}{|c|}{$\# \mathrm{n}=30$ for $\mathrm{Be}(\mathrm{ecf})$} \\
\hline
\end{tabular}

Laboratory experiments: Effects of changing resistance and compliance in one artificial lung on flow and pressure in the second lung

We performed the tests of mechanical property changes (named later 'events') in a first artificial lung $(A L)$ to the flow and pressure changes in a second $A L$ (the scheme of the laboratory setup is presented in Fig. S1, and its picture is presented in Fig. S2). The results are presented in Table 3 and Figures S3-S8. 
Table 3

Step changes (events) of the resistance $(R)$ and compliance $(C)$ in the object \#1 (left artificial lung). All pressures refer to respiratory peak pressure, expressed in $\mathrm{cmH} 2 \mathrm{O}$. All volumes refer to a respiratory tidal volume, expressed in ml. pre, index refers to the variable before the event; post, index refers to the variable after the event; $P 1, P 2$, pressures for object $\# 1$, \#2, respectively; $V 1, V 2$, volumes for object $\# 1$, \#2, respectively; $d P 1=P 1$ (post) $-P 1$ (pre); $d P 2=P 2$ (post) $P 1$ (post); $d P 1 \%$, relative percentage error for $d P 1 ; d P 2 \%$, relative percentage error for $d P 2 ; d V 1=V 1$ (post) - V1(pre); $d V 2=V 2$ (post) - V2(pre); $d V 1 \%$, relative percentage error for $d V 1 ; d V 2 \%$, relative percentage error for $d V 2$; "RX to $R Y$ " refers to the initial resistance $(X)$ and the resistance after the event $(Y)$, when the compliances are default $(C=75)$ and constant; " $C A$ to $C B$ " refers to the initial compliance $(A)$ and the compliance after the event $(B)$, when the resistances are default $(R=5)$ and constant; " $A L$ to Bag" refers to the exchanging the artificial lung $(R=5, C=75)$ to the $2 \mathrm{~L}$ respiratory bag $(R \sim 0, C \sim 15) ; R$ are expressed in

\begin{tabular}{|c|c|c|c|c|c|c|c|c|c|c|c|c|c|c|c|c|}
\hline $\begin{array}{l}\mathrm{RR}=12 \\
(1 / \mathrm{min})\end{array}$ & $\begin{array}{l}\text { P1 } \\
\text { (pre) }\end{array}$ & $\begin{array}{l}\text { P2 } \\
\text { (pre) }\end{array}$ & $\begin{array}{l}\text { P1 } \\
\text { (post) }\end{array}$ & $\begin{array}{l}\text { P2 } \\
\text { (post) }\end{array}$ & $\mathrm{dP1}$ & $\mathrm{dP} 2$ & $\mathrm{dP} 1 \%$ & $\mathrm{dP} 2 \%$ & $\begin{array}{l}\text { V1 } \\
\text { (pre) }\end{array}$ & $\begin{array}{l}\text { V2 } \\
\text { (pre) }\end{array}$ & $\begin{array}{l}\text { V1 } \\
\text { (post) }\end{array}$ & $\begin{array}{l}\text { V2 } \\
\text { (post) }\end{array}$ & $\mathrm{dV} 1$ & $\mathrm{dV} 2$ & $\mathrm{dV} 1 \%$ & $d V 2 \%$ \\
\hline $\mathrm{R} 5$ to $\mathrm{R} 20$ & 16,7 & 15,7 & 17,7 & 15,8 & 1,0 & 0,1 & 6,0 & 0,6 & 638 & 583 & 630 & 598 & $\div 8$ & 15 & $\div 1,3$ & 2,6 \\
\hline R5 to R50 & 16,5 & 16 & 30,4 & 16,1 & 13,9 & 0,1 & 84,2 & 0,6 & 614 & 603 & 653 & 597 & 39 & $\div 6$ & 6,4 & $\div 1,0$ \\
\hline R5 to R200 & 16,8 & 15,7 & 84,5 & 14 & 67,7 & $\div 1,7$ & 403,0 & $\div 10,8$ & 641 & 581 & 516 & 466 & $\div 125$ & $\div 115$ & $\div 19,5$ & $\div 19,8$ \\
\hline R5 to R0 & 16,8 & 15,7 & 1 & 15,3 & $\div 15,8$ & $\div 0,4$ & $\div 94,0$ & $\div 2,5$ & 639 & 584 & 627 & 590 & $\div 12$ & 6 & $\div 1,9$ & 1,0 \\
\hline $\mathrm{C} 75$ to $\mathrm{C} 60$ & 16,6 & 15,7 & 22,2 & 15,7 & 5,6 & 0 & 33,7 & 0,0 & 637 & 588 & 642 & 589 & 5 & 1 & 0,8 & 0,2 \\
\hline C75 to $\mathrm{C} 25$ & 16,7 & 15,6 & 27,5 & 15,5 & 10,8 & $\div 0,1$ & 64,7 & $\div 0,6$ & 646 & 581 & 658 & 563 & 12 & $\div 18$ & 1,9 & $\div 3,1$ \\
\hline $\mathrm{C} 60$ to $\mathrm{C} 75$ & 21,65 & 21 & 17 & 20 & $\div 4,7$ & $\div 1$ & $\div 21,5$ & $\div 4,8$ & 619 & 606 & 638 & 574 & 19 & $\div 32$ & 3,1 & $\div 5,3$ \\
\hline AL to Bag & 16,45 & 15,8 & 36,55 & 15,8 & 20,1 & 0 & 122,2 & 0,0 & 631 & 571 & 657 & 607 & 26 & 36 & 4,1 & 6,3 \\
\hline \multicolumn{17}{|l|}{$\begin{array}{l}\mathrm{RR}=18 \\
(1 / \mathrm{min})\end{array}$} \\
\hline $\mathrm{R} 5$ to $\mathrm{R} 20$ & 13,8 & 13,5 & 15 & 13,6 & 1,2 & 0,1 & 8,7 & 0,7 & 430 & 389 & 428 & 399 & $\div 2$ & 10 & $\div 0,5$ & 2,6 \\
\hline R5 to R50 & 13,9 & 13,5 & 28,4 & 13,8 & 14,5 & 0,3 & 104,3 & 2,2 & 422 & 400 & 442 & 406 & 20 & 6 & 4,7 & 1,5 \\
\hline R5 to R200 & 14 & 13,5 & 85 & 13,6 & 71,0 & 0,1 & 507,1 & 0,7 & 423 & 401 & 457 & 406 & 34 & 5 & 8,0 & 1,2 \\
\hline $\mathrm{R} 5$ to $\mathrm{R} 0$ & 13,8 & 13,6 & 1 & 12,8 & $\div 12,8$ & $\div 0,8$ & $\div 92,8$ & $\div 5,9$ & 424 & 400 & 438 & 387 & 14 & $\div 13$ & 3,3 & $\div 3,3$ \\
\hline C75 to $\mathrm{C} 60$ & 14 & 13,5 & 18,5 & 13,5 & 4,5 & 0 & 32,1 & 0,0 & 412 & 400 & 426 & 393 & 14 & $\div 7$ & 3,4 & $\div 1,8$ \\
\hline C75 to C25 & 14 & 13,4 & 24,7 & 13,5 & 10,7 & 0,1 & 76,4 & 0,7 & 425 & 401 & 438 & 409 & 13 & 8 & 3,1 & 2,0 \\
\hline C60 to C75 & 18,5 & 18 & 14,6 & 17,1 & $\div 3,9$ & $\div 0,9$ & $\div 21,1$ & $\div 5,0$ & 431 & 400 & 436 & 379 & 5 & $\div 21$ & 1,2 & $\div 5,3$ \\
\hline $\mathrm{AL}$ to $\mathrm{Bag}$ & 14 & 13,4 & 26,8 & 13,5 & 12,8 & 0,1 & 91,4 & 0,7 & 435 & 390 & 438 & 413 & 3 & 23 & 0,7 & 5,9 \\
\hline \multicolumn{17}{|l|}{$\begin{array}{l}\mathrm{RR}=24 \\
(1 / \mathrm{min})\end{array}$} \\
\hline $\mathrm{R} 5$ to $\mathrm{R} 20$ & 12,4 & 12,2 & 13,5 & 12,3 & 1,1 & 0,1 & 8,9 & 0,8 & 321 & 302 & 320 & 303 & $\div 1$ & 1 & $\div 0,3$ & 0,3 \\
\hline R5 to R50 & 12,4 & 12,3 & 27,7 & 12,5 & 15,3 & 0,2 & 123,4 & 1,6 & 321 & 305 & 341 & 312 & 20 & 7 & 6,2 & 2,3 \\
\hline R5 to R200 & 12,5 & 12,3 & 84 & 13,5 & 71,5 & 1,2 & 572,0 & 9,8 & 321 & 305 & 363 & 366 & 42 & 61 & 13,1 & 20,0 \\
\hline $\mathrm{R} 5$ to $\mathrm{R} 0$ & 12,4 & 12,3 & 1 & 11,3 & $\div 11,4$ & $\div 1$ & $\div 91,9$ & $\div 8,1$ & 321 & 306 & 334 & 292 & 13 & $\div 14$ & 4,0 & $\div 4,6$ \\
\hline C75 to $\mathrm{C} 60$ & 12,5 & 12,3 & 16 & 12,2 & 3,5 & $\div 0,1$ & 28,0 & $\div 0,8$ & 321 & 305 & 336 & 300 & 15 & $\div 5$ & 4,7 & $\div 1,6$ \\
\hline $\mathrm{C} 75$ to $\mathrm{C} 25$ & 12,5 & 12,3 & 21,5 & 12,4 & 9,0 & 0,1 & 72,0 & 0,8 & 319 & 300 & 331 & 310 & 12 & 10 & 3,8 & 3,3 \\
\hline C60 to C75 & 16,1 & 15,7 & 13 & 14,9 & $\div 3,1$ & $\div 0,8$ & $\div 19,3$ & $\div 5,1$ & 328 & 302 & 335 & 294 & 7 & $\div 8$ & 2,1 & $\div 2,6$ \\
\hline $\mathrm{AL}$ to $\mathrm{Bag}$ & 12,5 & 12,3 & 21,6 & 12,3 & 9,1 & 0 & 72,8 & 0,0 & 318 & 302 & 327 & 310 & 9 & 8 & 2,8 & 2,6 \\
\hline
\end{tabular}

The pressure change $(d P)$, defined as the difference between the PIP in one of the Ventil device output channels before and after the event, was obviously changed in the affected $A L(d P 2)$. The percentage relative error for $d P 2(d P 2 \%)$ was proportional to the simulated $R$ and $C$ changes. For the tested (not affected) $A L$, this pressure change ( $d P 1)$, expressed as a percentage relative error ( $d P 1 \%)$, was less than $10 \%$ for all cases, except ' $R 5$ to $R 200$ ' for the $R R=12$ event, where it was approximately $11 \%$. The $T V$ change ( $d V$ for affected and tested $A L$ ( $d V 1$ and $d V 2$, respectively) expressed as the percentage relative errors ( $d V 1 \%$ and $d V 2 \%$, respectively) were also less than $10 \%$ with two exceptions, which means that minute ventilation was retained in both channels for all except 2 of the simulated events. One exception was for ' $R 5$ to $R 200$ ' for $R R=12$. In this case, the inspiration was finished early by the ventilator due to the very high pressure in the ventilator output port (Fig. S3). Therefore, $d V 1 \%$ and $d V 2 \%$ were at the level of $-20 \%$. The second exception was for 'R5 to $R 200$ ' for $R R=24$. In this case, tidal volumes were approximately $13 \%$ and $20 \%$ higher $(d V 1 \%, d V 2 \%)$ for the tested and affected $A L$, respectively. The Ventil device was able only to split the gas flow. It is not a flow generator. The tidal volume increase, in this case, could be explained only by the measurement error of the flow sensors, or when used in the experiments, the ventilator flow generator was not independent of the load (output pressure).

These experiments show Ventil strong endurance in keeping division of the minute ventilation when the respiratory system $R$ and $C$ parameters are changed (respiratory deterioration or improvement of a patient). Ventil stabilized the ventilation within a few respiratory cycles after an adverse event had occurred. 
Other laboratory experiment results using the same setup (Fig. S1-S2) are described in the supplementary materials and are presented in Fig. S9-Fig. S15.

\section{Simulation of cross-contamination - laboratory tests}

Research on the transmission of particles in the dual tract respiratory system with Ventil was carried out in two stages with the use of 1) aqueous solutions of fluorescent compounds and 2) suspension of the SARS-CoV-2 coronavirus phantom in the form of fluorescent nanospheres. The presence of test substances and nanoparticles was examined at test points $T 1, T 2$ and $T 3$. The results are presented in Supplement R1 in the form of a technical report on the transmission of solutions/nanoparticles in two respiratory branches of the Ventil system. There were no fluorescein traces on the postfiltering side of the filters located at test points $T 1, T 2$ and $T 3$. No traces of fluorescein were observed on the postfiltering surface filter surface for the filter placed at test point $T 3$. Furthermore, used in our experiments under most critical conditions, when electrostatic filter $F$ and the $P E E P$ valve were removed, viral phantoms in the form of fluorescently labeled nanospheres with a diameter of $100 \mathrm{~nm}$ in the stream of air exhaled from the left lung did not spread further than to the filtering surface of the filter at test point $T 3$.

In summary, based on the conducted technical studies related to the assessment of the possibility of transmission of solutions/suspensions in two respiratory branches of the Ventil system, it was found that under the conditions of the experiment with the use of fluorescent solutions and suspensions, no transmission occurred.

\section{Discussion}

The experiments were conducted on animals with similar weights and on animals with significant weight differences for simulating human patients with similar properties of the respiratory system (resistance and compliance) versus patients with respiratory systems with different properties. The obtained results show that the ventilation of two animals can be effectively continued for at least 24 hours by the ventilator and Ventil device independent of the body weight difference in the pair. The results also confirm the stabilization of animals' oxygenation, ventilatory status and acid-base balance and demonstrate that the weight difference can be effectively compensated using the Ventil device by adjusting TV pumped into the lungs of both animals. We were trying to apply the lung protective strategy; thus, we retained the elevated $p \mathrm{CO} 2 / E t C O 2$ levels. Object-specific minute ventilation can be maintained according to the following rules:

If subject \#1 requires increased minute ventilation due to, for example, elevated $p C O 2 / E t C O 2$ and subject \#2 requires decreased minute ventilation due to reduced $p C O 2 / E t C O 2$ - adjust flow division by the knob in the Ventil device.

If subject \#1 requires increased/decreased minute ventilation and for subject \#2, the mechanical ventilation is proper - in small steps, change the ventilator parameters to increase/reduce the ventilation and in parallel change the flow division by the knob in the Ventil device.

If both subjects require increased/decreased minute ventilation - iteratively change the parameters in the ventilator and optionally adjust the flow division in the Ventil device.

For both animal groups, the statistical analysis showed that there was no complete evidence of the differences between the ABG parameters of the ventilated animals in relation to time. These results did not show significant differences in dynamic changes in $A B G$ parameters. The obtained results may constitute a clinical implication indicating the acceptable level of safety for ventilation using the Ventil device in the evaluated groups of animals independent of the body weight in the pair ventilated by the same Ventil device. Moreover, the lung $C T$ scan analysis carried out before and after long-term ventilation did not reveal serious injuries, such as emphysema, pneumothorax and pleural effusion caused by the ventilation procedure. Taken together, the results indicate that the saved respiratory $\Delta P$ value for ventilated pigs is $<10 \mathrm{cmH} 20$.

During the evaluation of the obtained results of the $A B G$, our attention was given to the direction and range of changes over time. SaO2, $p H$ and lactate concentration were maintained in the normal range. The results of $p O 2$ were high in both groups. Our results in the WS group are comparable with the results reported by Bitelia et al. for the group of pigs ventilated with oxygen and compressed air FiO2 0.5/air (32). The WD group showed lower values than WS but within the normal range for all time points. The $\mathrm{pCO} 2$ showed high values that are comparable with values reported by others (32, 33). The value of $\mathrm{CHCO}^{-}$ remains at a high level, a trend of changes similar to $\mathrm{pCO}$. High values of $\mathrm{CHCO}^{-}$and the same trend as $\mathrm{pCO} 2$ may indicate that elevated $\mathrm{CHCO}^{-}$is a metabolic response to $\mathrm{pCO}$, especially when changes in blood oxygenation and a low lactate concentration indicate adequate tissue oxygenation. Taking into account the time of observation, we presume that two of three compensatory systems, extracellular and respiratory, can be responsible for it. The renal compensatory system acts slowly to compensate for acid-base balance (34). Among several factors that can be responsible for the obtained results of $p$ CO2 and $\mathrm{CHCO}^{-}$, the primary cause should be sought in disorders of $\mathrm{CO} 2$ exchange due to changes in the position of pigs from side to back that can induce disturbances in gas exchange between perfusion and ventilation.

Furthermore, in an animal experiment in which dynamic changes in lung compliance were enforced, the results indicated that the automatic airflow control system applied in Ventil correctly responded to the progressive changes in the lung compliance of subject \#1, which again allowed the maintenance of respiratory mechanical parameters during the ventilation process. However, flow level inequality is mainly related to the dispersion of two analog flow sensors in the Ventil, and the dispersion of Ventil analog electronic component parameters produces the flow signal bias and causes the volume division to not be exactly as expected. The inequality of flow levels can occur when the higher maximum flow is set in a ventilator. In animal experiments, the set flow was approximately $40 \mathrm{~L} / \mathrm{min}$ per channel, whereas it was approximately $20 \mathrm{~L} / \mathrm{min}$ in laboratory experiments. Therefore, in laboratory experiments, flow inequality was smaller. In conclusion, the Ventil is more sensitive to respiratory compliance changes than to resistance changes in the subject. However, the laboratory results in maintaining $M V$ in both channels (when $R$ and $C$ are changed) are still acceptable and can be somewhat corrected by the Ventil flow division knob. 
Abrupt variation in compliance is a rare situation in clinical practice. In the case of rapid occlusion for one patient, the Ventil can maintain the second patient's MV.

The results of animal and laboratory experiments suggest that the ventilation of two patients can be performed using a single ventilator and the airflow divider Ventil. The proposed system and ventilation procedure allowed the animals' ventilation while maintaining the tested parameters at a stable level during one-day-long ventilation; therefore, it can be considered safe. Moreover, even Ventil system malfunction did not introduce rapid mechanical ventilation changes for ventilated objects (Fig. S9-S14). The worst-case scenario is when one Ventil channel delivers minimal gas volume (dividing head in the Ventil is constructed to make it mechanically impossible to close one of the channels or both of them) to the patient due to electronic and control system failure, and the remaining portion of the gas volume is delivered to the second channels (second patient). We did not use pressure relief valves in our animal experiments due to continuous supervision and external subject monitoring. However, they must be applied in the respiratory circuit in clinical settings (10). These valves prevent excessive ventilation in patients. Using Ventil devices, the operator must also take care of when an extensible, flexible tube between the ventilator and the Ventil is used. In our laboratory experiments, too rapid stretching of this tube caused a ventilator (Bennett 840) malfunction. The ventilator safety valve was activated, and the ventilator was switched into the service mode. This was probably due to the negative pressure created between the ventilator and the ventilator.

The Ventil system can be easily adjusted to the oxygen demands related to the mismatch of weight (and, thus, the lungs' size) of both ventilated objects by tuning the respiratory tidal volume division between them. A similar but "manual" approach is the solution based on manually titrated pneumatic valves. The ventilation strategy based on the automatic adjustment of the airflow in both branches of the Ventil divider is effective even in case of dynamic changes in resistance and compliance of both subjects' lungs. Thus, the respiratory resistance or compliance changes appearing in one subject do not influence the other subject's ventilation. Similar results presented by Srinivasan et al. relied on manual adjustment of airflow in both branches of the divider and were limited to assessing the feasibility of such a procedure in a pig after euthanasia (10).

Additional mechanical PEEP valves can be used with Ventil to differentiate intrinsic $P E E P(P E E P I)$ levels during therapy. In animal experiments, mechanical, fixed $P E E P$ valves were used. However, neither ventilator that we used cooperated when fixed $P E E P$ valves of $5 \mathrm{cmH} 20$ or higher were used. The occlusion alarm was indicated by both ventilators immediately. The PEEP valves 2.5 and $0 \mathrm{cmH} 20$ (only one-way valves) worked correctly. Therefore, extrinsic $P E E P$ (PEEPe) values were also set in the ventilator. PEEPi in the lungs of the subject at the end of the expiration is a sum of set $P E E P e$ and mechanical $P E E P$ valves. Other authors in their studies neglect differential $P E E P$ levels (12) and use only a shared $P E E P$ set in a ventilator. However, various $P E E P$ levels for ventilated patients in shared ventilation systems are an open issue. Combining the mechanical $P E E P$ valve with a $P E E P$ set in the ventilator caused the mechanical $P E E P$ valve outlet to experience positive pressure. This valve is often a component of continuous positive airway pressure (CPAP) systems designed to work in conditions with 0 (atmospheric) pressure at the outlet. Its long-term reliability under atypical applications should be confirmed in further tests.

Ventilator alarms and monitoring management in the case of shared ventilation is an additional challenge $(10,16,35)$. Our experience confirmed the requirements described by other authors (10-12). For 1:1 division, the peak pressure difference between the Ventil outputs and measured by the ventilator can be up to $20 \mathrm{cmH} 20$ for a flow level of approximately $100 \mathrm{~L} / \mathrm{min}$ (Fig. S15). Peak pressure values in the ventilator can then be elevated, and the high-pressure alarm must be corrected. The Ventil displays only the mean pressure in the output ports and the mean flow for both channels. Therefore, external monitoring is still necessary for both patients (10). A low mechanical ventilation alarm is also essential to prevent leakages in the whole respiratory circuit (35).

Nonsynchronized activities of both patients may lead to dynamic changes in the pressure of the airways and significant disturbances in the ventilation mechanics of one or both subjects. Thus, patients with maintained respiratory function need deep sedation $(10,11,16)$ to avoid nonsynchronous respiratory activities in both ventil device branches. Although the shared ventilation approach can be applied in COVID-19 patients (35), it is worth considering the shared ventilation system in other groups of patients, potentially allowing ventilators to be saved for use in treating patients with COVID-19. The clinical safety of such treatment needs to be confirmed in further clinical tests.

Most of the previous studies aimed to validate the potential usefulness of ventilation in two or more patients using a single ventilator were based on laboratory experiments in which only test lungs were used $(6,9,12,16,36)$. Only a few animal experiments were carried out $(7,10)$. Preliminary tests on a few pairs of patients were reported in which the feasibility of ventilator sharing for COVID-19-associated ARDS was demonstrated (35, 37). The ventilation strategies reported recently in the context of the treatment of COVID-19 patients and based on the utilization of a single ventilator and an airflow divider provoked a global discussion on the limitations and safety of such approaches in emergencies $(38,39)$. Nevertheless, this discussion is limited due to the lack of clinical studies focused on the safety and effectiveness of respiratory support using a single ventilator shared by two or more patients.

Among the other problems, there is the aforementioned one related to possible cross-contamination of both patients' respiratory tracts. Similar to the results obtained by other authors, there was no transmission of solutions of fluorescent dyes - trypan blue (10), neither fluorescein nor methylene blue - as indicated in our study presented in Report R1 in the supplementary materials. Concerning the studies described in (10), which include continuous nebulization of 5 ml of trypan blue solution for 10 minutes and visual observation of the filters, in our experiment, in addition to the use of fluorescein and methylene blue solutions, we proposed a pathogen transmission study method using phantoms of the virus in the form of nanospheres with a diameter of $100 \mathrm{~nm}$ internally labeled with fluorescent dyes, the concentration of which in the administered suspension was approximately 24.1012 particles/3 mL, which corresponds to a viral titer of ca. 1000-fold excess with respect to SARS-CoV-2 titer after 5-day incubation of infected Calu3 cells (21). The proposed method using nanoparticles can be safely carried out in the laboratory environment, obtaining more specific, in relation to acquisition from experiments with solutions, preliminary information about the possibility of cross-transmission in the respiratory tract during independent ventilation of artificial lungs.

\section{Conclusions}


In conclusion, the Ventil device might be considered to ventilate two patients by one ventilator with an acceptable safety level. It meets the same challenges as other shared ventilation systems. However, it automatically stabilizes the patients' minute ventilation and is highly invulnerable to the patients' respiratory resistance and compliance changes. The Ventil system is notwithstanding for differential lung ventilation and can still be applied in respiratory therapy in asymmetrical lung pathology or thoracic surgery. Additionally, it can be used in emergency situations when the lack of ventilatory support for a large number of patients is expected, such as during terrorist attacks or widespread respiratory function diseases.

\section{Methods}

\section{Ventil device}

Ventil is a device originally developed for differential mechanical lung ventilation and can be used in one-lung ventilation as well as in the case of asymmetric lung pathologies. It splits the flow according to the selected ratio (by a division knob). However, it must be emphasized that the Ventil is not a simple splitter of the flow from the ventilator. It is a device that can adjust minute ventilation, keeping the parameters stable regardless of changes in the air duct properties of the lungs. The division of the flow is stabilized by two flowmeters, continuously measuring the flows in output ports and sending these flow signals to the control system, which then corrects the splitting to maintain the flow division according to the selected ratio. External mechanical or electromagnetic (fixed or adjustable) positive end-expiratory pressure $(P E E P)$ valves can be used with the Ventil. Therefore, the PEEP for both lungs can also be regulated. The Ventil requires one-way valves to separate tracks (particular lung circuits) and protect from gas mixing from these tracks. Instead of two lungs, Ventil can be technically used to ventilate two patients.

\section{The test stand during experiments on animals}

Two Puritan Bennett 980 and 840 ventilators (Medtronic, Minneapolis, MN) and two Anastazja 7700 anesthesia ventilators (Farum Ltd., Warsaw, Poland) were used with two Ventil devices (serial numbers SN0022 and SN0024). Four patient monitors (Datex-Ohmeda S/5, GE Healthcare, Boston, MA) were used with the E-PRESTN module (GE Healthcare, Boston, MA). Three of them were also equipped with an E-CAIOV module (GE Healthcare, Boston, MA). Data from patient monitors were collected by Windows 10 PC-based computers. We calculated the median and interquartile range (IQR) values for the following continuously recorded signals during the experiments: oxygen saturation (SpO2), oxygen inspiratory fraction (FiO2), end-tidal carbon dioxide partial pressure (EtCO2), peak inspiratory pressure $(P I P), P E E P$, respiratory rate $(R R)$, tidal volume $(T V$ and calculated parameters: driving pressure $(\triangle \mathrm{P})$, minute ventilation $(M V)$ and static compliance (Cst). The $M V$ was an inspired tidal volume times $R R$. The driving pressure was calculated as the difference between a plateau pressure (Pplat) and positive end-expiratory pressure (Pplat - PEEP). The static compliance was the ratio of the expired TV and the driving pressure. These 3 parameters were calculated per recorded sample. The statistics were processed for all pigs used in the experiments. The spirometric variables were not recorded by the fourth patient monitor due to the E-CAIO (GE Healthcare, Boston, MA) instead of the E-CAIOV module implemented (the E-CAIO module does not measure spirometric variables, in contrast to the E-CAIOV module). All recorded data were postprocessed by MATLAB R2019b and MS Excel 2019 software.

Two Ventil flowmeters (Ventil outputs) were connected with inspiratory arms of two adult polypropylene (PP) anesthesia extendible $60 / 180 \mathrm{~cm}$ breathing circuits with Y-pieces (Medtronic, Minneapolis, MN) by Fixed elbow 22 M - 7.6 mm port - 22 M/15F connectors (Intersurgical, New York, NY) and electrostatic antibacterial and antiviral filters Barrierbac S 22 M/15F (Medtronic, Minneapolis, MN) in series. The Y-pieces were connected with animals by electrostatic filters (various vendors), and the patient monitored probes. The animals' expiratory limps were connected to electrostatic antibacterial and antiviral filters Barrierbac S 22 M/15F (Medtronic, Minneapolis, MN), one-way valves (Intersurgical, New York, NY), and 2.5 cmH2O PEEP valves (Intersurgical, New York, NY or Flexicare, Mountain Ash, Great Britain). The PEEP valve output was connected (through $30 \mathrm{M}-22 \mathrm{M}$ (Intersurgical, New York, NY) or $22 \mathrm{M}-22 \mathrm{M} / 15 \mathrm{~F}$ (R-Vent Medikal, İzmir, Turkey) connectors) by third adult PP anesthesia extensible 60/180 cm breathing circuits (Medtronic, Minneapolis, MN) to the ventilator (Ypiece site) by a 22F-22F connector (Intersurgical, New York, NY). The configuration is presented in Fig. 1A.

\section{Animal use protocol}

This animal study was approved by the First Bioethical Commission in the Ethics Committee for Animal Experiments in Warsaw (agreement no WAW2/047/2020). All methods were carried out in accordance with relevant guidelines and regulations and reported in accordance with ARRIVE guidelines (https://arriveguidelines.org). After obtaining the approval, the animals (pigs) were classified for testing; males and females of the Great White Polish Breed, aged approximately 3-6 months. The choice of pigs was based on the assumption of similarity of body and lung mass and therefore ventilation parameters to humans, tidal volume $6-8 \mathrm{ml} / \mathrm{kg}$. Preparation for qualified animals was carried out according to an established schedule. Prior to intubation and mechanical ventilation, animals received premedication: medetomidine 0.05-0.1 mg/kg (Cepetor $1 \mathrm{mg} / \mathrm{ml}$, ScanVet Ltd., Warsaw, Poland), butorfanol 0.1-0.2 mg/kg (Butomidor 10 ml, Richter Pharma AG, Wels, Austria), ketamine 5-10 mg/kg (Bioketan, Vetoquinol Biowet Ltd., Gorzów Wielkopolski, Poland) as an intramuscular injection (buttock muscles). After securing an intravenous line (BD Venflon $1.2 \mathrm{~mm}$, Becton Dickinson, Franklin Lakes, NJ) with access to the posterior ear vein (vena auricularis posteriori), the animals were induced into general anesthesia with propofol (Scanofol $10 \mathrm{mg} / \mathrm{ml}$, ScanVet Ltd., Warsaw, Poland) at a dose based on body weight. After intubation (body weight-dependent tube number), general anesthesia was conducted with isoflurane (Aerrane Baxter, Healthcare Baxter Inc., Warsaw, Poland) in a volumetric percentage adequate to the induced clinical effect, starting with a concentration of 5 vol\%, with a continuation of 2 vol\%. Subsequently, the anesthetized animals underwent a computer tomography scan (lungs were inflated with air) and then were connected to the anesthesia machine or ventilator by the Ventil. All animals under this experiment had artery cannulas placed in the iliac artery and a central intravenous line in the iliac vein, and both were used to assess cardiovascular indices and to obtain blood samples for laboratory tests. For all objects, a bladder catheter was also placed to assess diuresis. Anesthesia was conducted with isoflurane during the experiment when animals were ventilated by an anesthetic machine, while propofol was applied in those experiments when the ventilator was used. Arterial blood gas $(A B G)$ samples were collected and analyzed by a blood analyzer (epoc® Blood Analysis System, Siemens Healthineers, Erlangen, Germany) in terms of the activity of hydrogen ions ( $p H$ ), carbon 
dioxide partial pressure ( $p C O 2)$, oxygen partial pressure ( $p O 2)$, bicarbonate concentration ( $H C O 3)$, base excess in the extracellular fluid ( $B E$ (ecf)), oxygen saturation of hemoglobin ( $\mathrm{SaO}$ ) and lactate level. $A B G$ samples were collected at $0,5,12,17$, and 24 hours of the experiment from all objects (except experiment 3 , when they were recorded at $0,2,4,6,8$, and 10 hours). After the experiment, a computer tomography scan was repeated for all animals.

\section{Statistical analysis}

The Mann-Whitney $\mathrm{U}$ test was used to compare the differences between all values of $A B G$ parameters in pairs with similar weights (WS) and different weights $(W D)$ groups acquired across the experiments because the distribution of these parameters differed from the normal distribution and because for most of them, the homogeneity of variances was not fulfilled. The Friedman test and Spearman's rank correlation were performed to analyze the repeatable $A G B$ parameters measured at fixed intervals of time. The analyses were performed separately for each of the parameters for the WS and WG groups separately. The value for a statistically significant difference was set at a $=0.05$ for all statistical analyses. The Statistica v.13.3 software package was used for the calculations.

\section{Laboratory test bench}

A Ventil with serial number SNOOO3 with two flowmeters (SpiroQuant $\mathrm{H}$, EnviteC, Germany) was used. Two elbow connectors with luer-lock ports (22 M/15Fand straight connectors (22 M-22 M and 22F-22F) connected the Ventil flowmeters and the air-gas flowmeters SFM3000 (Sensirion, Switzerland). Two adult PP anesthesia extendible 60/180 cm breathing circuits with Y-pieces (Medtronic, Minneapolis, MN) were connected to SFM 3000 (inspiratory arms) with artificial test lungs SmartLung 2000 (IMT Analytics, Switzerland) through HMEF filters. Expiratory limps were connected to electrostatic antibacterial and antiviral filters Barrierbac S 22 M/15F (Medtronic, Minneapolis, MN), one-way valves (Intersurgical, New York, NY), and $2.5 \mathrm{cmH} 20$ PEEP valves (Intersurgical, New York, NY). The PEEP valve output was connected (through $30 \mathrm{M}-22 \mathrm{M}$ connectors (Intersurgical, New York, NY)) by third adult PP anesthesia extensible $60 / 108 \mathrm{~cm}$ breathing circuits (Medtronic, Minneapolis, MN) to the ventilator (Y-piece site) by a 22F-22F connector (Intersurgical, New York, NY). Luer-lock ports were connected with 143SC01D-PCB pressure sensors (Sensortechnics GmbH, Germany). These pressure sensors and SFM3000 flow sensors are part of the measurement system. Pressure signals were recorded by the real-time NI PXI-1042 system with a NI PXI-6289 data acquisition board installed (both of them National Instruments, Austin, TX). Flow data from SFM3000 flow sensors were recorded by the STM32VLDISCOVERY board (STMicroelectronics, FranceItaly). All pressure and flow data were collected by a Windows 7 PC laptop with its own developed software in LabVIEW 2013 (National Instruments, Austin, TX) for data storage and visualization. The configuration is presented in Fig. S1. The picture with the given setup is shown in Fig. S2.

\section{Laboratory experiments: Effects of changing resistance and compliance in one artificial lung $(\mathrm{AL})$ on flow and pressure in the second lung}

We changed the resistance ( $R$, all values expressed in $\mathrm{mbar} / \mathrm{L} / \mathrm{s})$ from the baseline value $R=5$ to values $20(R 5$ to $R 20), 50(R 5$ to $R 50)$ and $200(R 5$ to $R 200)$ and compliance ( $C$, all values expressed in $\mathrm{mL} / \mathrm{mbar}$ ) from baseline value $C=75$ to values 60 ( $C 75$ to $C 60$ ) and 25 (C75 to $C 25$ ) as well as from $C=60$ (for both $A L$ ) to $C=75$ (C60 to $\mathrm{C} 75)$. We also performed breathing circuit disconnection (in the patient's filter point - P1 marker in Fig. S1) tests $(R 5$ to $R 0$ ) and replaced the first $A L(R=5, C=75)$ with the 2 liters respiratory bag (Medtronic, Minneapolis, MN) with the $R \sim 0$ and $C \sim 15$ ( $A L$ to Bag). The second $A L$ parameters were not affected during the experiments. For the ' $R 5$ to $R 20$ ', ' $R 5$ to $R 50$ ', ' $R 5$ to $R 200$ ' and ' $R 5$ to $R O$ ' events, a baseline $C=75$ value was used. For the ' $C 75$ to $C 60$ ', 'C75 to $C 25$ ' and ' $C 60$ to $C 75$ 'events, a baseline $R=5$ value was used. Baseline $R=5$ and $C=75$ values were used for $A L$ in the ' $A L$ to $B a g$ ' event. We investigated how the pressure and delivered tidal volume were changed in the \#2 $A L$ (expressed by index 2 for pressures and volumes in Table 3 ) when the parameters of the $\# 1 A L$ were changed (pressures and volumes in Table 3 for this $A L$ are expressed by index 1 ). All tests were performed for three respiratory rate values of 12,18 , and 24 breaths/min.

\section{Simulation of cross-contamination}

The experimental measurement system and conditions are described in supplement R1 - Technical Report of IBBE PAS on the transmission of nanoparticles/solutions in two respiratory branches of the Ventil system for experiments carried out in the period April 4 - 29, 2020. Figure R1 (technical report R1) shows a diagram of the test system with the Ventil apparatus supplying the respiratory tract during independent ventilation of two artificial lungs (right and left). Left: Right flow ratio 6:4. To test the possibility of transmission between the two airways, the test solutions and suspensions of phantoms were administered to the expiratory tract of the artificial $L$ lung using an Areogen nebulizer $(M)$ in $3 \mathrm{~mL}$ portions repeated several times. The checkpoints for the presence of test fluorescent substances and nanoparticles were at test points $T 1, T 2$, and $T 3$. In experiments, fluorescent compounds, such as sodium fluorescein (fluorescein) and methylene blue, purchased from Sigma and fluorescent red and green polystyrene nanospheres (red fluorescent polystyrene microspheres - EPRUI-RF-100C and green fluorescent polystyrene microspheres - EPRUI-GF-100C) with a diameter of $100 \mathrm{~nm}$ were used as virus phantoms. The stable fluorescence of the nanospheres was ensured by the incorporation of the dye inside them (so-called internal labeling). Fluorescein and methylene blue solutions of concentration of $1 \mathrm{mM}$ were used. In contrast, fluorescent nanospheres were administered as a $60 \mu \mathrm{L}$ suspension and $240 \mu \mathrm{L}$ stock suspension (provided by the manufacturer) per $3 \mathrm{~mL}$ of deionized water. Then, the estimated number of nanospheres in the prepared suspensions was 6.5.1012 and 24.1012 particles per $3 \mathrm{~mL}$, respectively.

\section{Declarations}

Acknowledgments: We would like to thank Dr K.J. Pałko from IBBE PAS and the $Ł$-ITAM team for Ventil device development and commercialization, including its certification process.

Funding: This study was supported by the Polish Ministry of Science and Higher Education (agreement no 21/WFSN/2020 from $18^{\text {th }}$ of March 2020),

\section{Author contributions:}


Conceptualization: KZ, DP, AL, MD, PŁ. Methodology: KZ, BL, AL, ZG, PŁ. Investigation: KZ, BL, KS, MS, KF, MB, JO, KA, AJ, MG, PO, MM, DP, KP, ER, RZ, KKR, AS, RP. Visualization: KZ, BL. Funding acquisition: AL, Pt. Project administration: Pt. Supervision: ZG, Pt. Writing - original draft: KZ, BL, DP, MD, AL, ZG, Pt. Writing - review \& editing: All authors.

Competing interests: AuthorsThe authors declare that they have no competing interests.

Data and materials availability: All data are available in the main text or the supplementary materials, except CT scans. The CT scans are available from the corresponding author upon reasonable request.

\section{References}

1. Ranney, M. L., Griffeth, V. \& Jha, A. K. Critical Supply Shortages - The Need for Ventilators and Personal Protective Equipment during the Covid-19 Pandemic. N Engl J Med. 382, e41 (2020).

2. Grasselli, G., Pesenti, A. \& Cecconi, M. Critical Care Utilization for the COVID-19 Outbreak in Lombardy, Italy: Early Experience and Forecast During an Emergency Response. JAMA. 323, 1545-1546 (2020).

3. Marini, J. J. \& Gattinoni, L. Management of COVID-19 Respiratory Distress. JAMA. 323, 2329-2330 (2020).

4. White, D. B. \& Lo, B. A Framework for Rationing Ventilators and Critical Care Beds During the COVID-19 Pandemic. JAMA. 323, 1773-1774 (2020).

5. Dhanani, J. et al. Increasing ventilator surge capacity in COVID 19 pandemic: design, manufacture and in vitro-in vivo testing in anaesthetized healthy pigs of a rapid prototyped mechanical ventilator. BMC Res Notes. 13, 421 (2020).

6. Neyman, G. \& Irvin, C. B. A single ventilator for multiple simulated patients to meet disaster surge. Acad Emerg Med. 13, 1246-1249 (2006).

7. Paladino, L. et al. Increasing ventilator surge capacity in disasters: Ventilation of four adult-human-sized sheep on a single ventilator with a modified circuit. Resuscitation. 77, 121-126 (2008).

8. Sommer, D. D., Fisher, J. A., Ramcharan, V., Marshall, S. \& Vidic, D. M. Improvised automatic lung ventilation for unanticipated emergencies. Crit Care Med. 22, 705-709 (1994).

9. Branson, R. D., Blakeman, T. C., Robinson, B. R. \& Johannigman, J. Use of a Single Ventilator to Support 4 Patients: Laboratory Evaluation of a Limited Concept. Respir Care. 57, 399-403 (2012).

10. Srinivasan, S. S. et al. A rapidly deployable individualized system for augmenting ventilator capacity. Sci Trans/ Med. 12 (2020).

11. Tonetti, T. et al. One ventilator for two patients: feasibility and considerations of a last resort solution in case of equipment shortage. Thorax. 75, 517519 (2020).

12. Jongh, F. H. C. de et al. Ventilating two patients with one ventilator: technical setup and laboratory testing. ERJ Open Res. 6 (2020).

13. Levin, M. A. et al. Differential Ventilation Using Flow Control Valves as a Potential Bridge to Full Ventilatory Support during the COVID-19 Crisis. Anesthesiology 133, 892-904 (2020).

14. Castañón-González, J. A. et al. Simultaneous mechanical ventilation of several patients with a single ventilator. Gac Med Mex. 156, 249-252 (2020).

15. Chatburn, R. L., Branson, R. D. \& Hatipoğlu, U. Multiplex Ventilation: A Simulation-based Study of Ventilating Two Patients with One Ventilator. Respiratory Care 65, (2020).

16. Han, J. S. et al. Personalized Ventilation to Multiple Patients Using a Single Ventilator: Description and Proof of Concept. Crit Care Explor. 2, e0118 (2020).

17. Laffey, J. G., Chikhani, M., Bates, D. G. \& Hardman, J. G. Supporting more than one patient with a single mechanical ventilator: useful last resort or unjustifiable risk? Br J Anaesth. 125, 247-250 (2020).

18. Cherry, A. D., Cappiello, J., Bishawi, M., Hollidge, M. G. \& MacLeod, D. B. Shared Ventilation: Toward Safer Ventilator Splitting in Resource Emergencies. Anesthesiology 133, (2020).

19. Cevik, M. et al. SARS-CoV-2, SARS-CoV, and MERS-CoV viral load dynamics, duration of viral shedding, and infectiousness: a systematic review and metaanalysis. The Lancet Microbe. 2, e13-e22 (2021).

20. Han, M. S. et al. Viral RNA Load in Mildly Symptomatic and Asymptomatic Children with COVID-19, Seoul, South Korea. Emerg Infect Dis. 26, 2497-2499 (2020).

21. Chu, H. et al. Comparative tropism, replication kinetics, and cell damage profiling of SARS-CoV-2 and SARS-CoV with implications for clinical manifestations, transmissibility, and laboratory studies of COVID-19: an observational study. The Lancet Microbe. 1, e14-e23 (2020).

22. Muth, D. et al. Infectious Middle East Respiratory Syndrome Coronavirus Excretion and Serotype Variability Based on Live Virus Isolates from Patients in Saudi Arabia. J Clin Microbiol. 53, 2951-2955 (2015).

23. Wölfel, R. et al. Virological assessment of hospitalized patients with COVID-2019. Nature. 581, 465-469 (2020).

24. Bullard, J. et al. Predicting Infectious Severe Acute Respiratory Syndrome Coronavirus 2 From Diagnostic Samples. Clin Infect Dis. 71, 2663-2666 (2020).

25. Arons, M. M. et al. Presymptomatic SARS-CoV-2 Infections and Transmission in a Skilled Nursing Facility. N Engl J Med. 382, 2081-2090 (2020).

26. La Scola, B. et al. Viral RNA load as determined by cell culture as a management tool for discharge of SARS-CoV-2 patients from infectious disease wards. Eur J Clin Microbiol Infect Dis 39, 1059-1061 (2020).

27. Darowski, M. \& Englisz, M. Artificial ventilation of the lungs for emergencies. Front Med Biol Eng. 10, 177-183 (2000). 
28. Darowski, M., Hedenstierna, G. \& Baehrendtz, S. Development and Evaluation of a Flow-Dividing Unit for Differential Ventilation and Selective PEEP. Acta Scandinavica. 29, 61-66 (1985).

29. Hedenstierna, G., Baehrendtz, S., Darowski, M. \& Frostell, C. Practical aspects of differential ventilation with selective peep in acute respiratory failure. Int J Clin Monit Comput. 1, 5-11 (1984).

30. Kowalczyk, M. et al. Successful 1:1 proportion ventilation with a unique device for independent lung ventilation using a double-lumen tube without complications in the supine and lateral decubitus positions. A pilot study. PLoS One. 12, e0184537 (2017).

31. Sawulski, S. Independent lung ventilation for treatment of post-traumatic ARDS. Anaesthesiology Intensive Ther. 44, 96-99 (2019).

32. Biteli, E. G. F. et al. Blood gas analysis in pigs submitted to different concentrations of nitrous oxide or oxygen, under different ventilatory modalities. Arquivo Brasileiro de Medicina Veterinária e Zootecnia. 71, 35-43 (2019).

33. Bekheit, M., Bucur, P., Vibert, E. \& Anders, C. The reference values for hepatic oxygen consumption and net lactate production, blood gasses, hemogram, major electrolytes, and kidney and liver profiles in anesthetized large white swine model, Translational Surgery 1, 95-100 (2016).

34. Edwards, S. L. Pathophysiology of acid base balance: The theory practice relationship. Intensive and Critical Care Nursing. 24, 28-40 (2008).

35. Beitler, J. R. et al. Ventilator Sharing during an Acute Shortage Caused by the COVID-19 Pandemic. Am J Respir Crit Care Med. 202, 600-604 (2020).

36. Rodríguez-Villar, S. Sharing a single ventilator ("In vitro"). Med Intensiva. 44, 514-516 (2020).

37. Milner, A., Siner, J. M., Balcezak, T. \& Fajardo, E. Ventilator Sharing Using Volume-controlled Ventilation during the COVID-19 Pandemic. Am J Respir Crit Care Med. 202, 1317-1319 (2020).

38. Mancebo, J., Richard, J.-C. \& Brochard, L. Ventilator Sharing during Shortages. A Siren's Song? Am J Respir Crit Care Med. 202, 490-491 (2020).

39. Chase, J. G. et al. In-Parallel Ventilator Sharing during an Acute Shortage: Too Much Risk for a Wider Uptake. Am J Respir Crit Care Med. 202, 1316-1317 (2020).

\section{Figures}

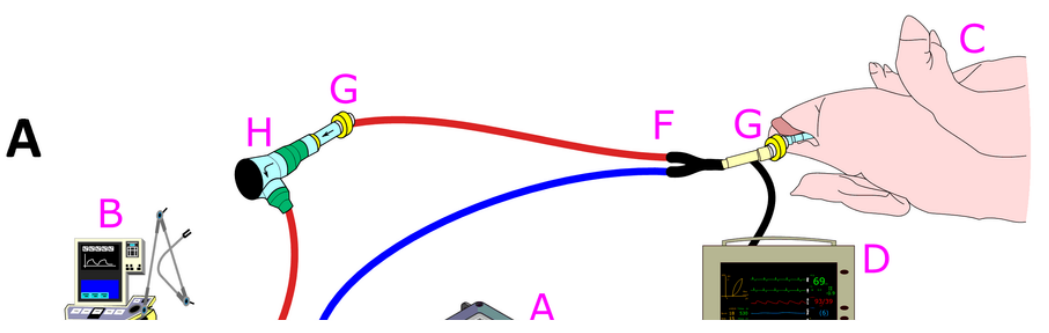

Figure 1 
Ventilation of two pigs was performed with a Ventil device and a ventilator. (A) Animal experiments test stand. A, Ventil device; B, ventilator or anesthetic machine; C, ventilated object; D, patient monitor; E, adult polypropylene extendible limb 22F-22F; F, adult polypropylene anesthesia extendible breathing circuits with $\mathrm{Y}$-pieces; $\mathrm{G}$, antibacterial and antiviral filter; $\mathrm{H}$, positive end-expiratory valve with one-way valve and set of connectors. (B) Animal experiments configuration. Ventilation of different animal pairs by the Ventil device together with the anesthetic machine or the ventilator. \#1, the first ventilated object; \#2, the second ventilated object; WS, similar weight group; WD, different weight group.

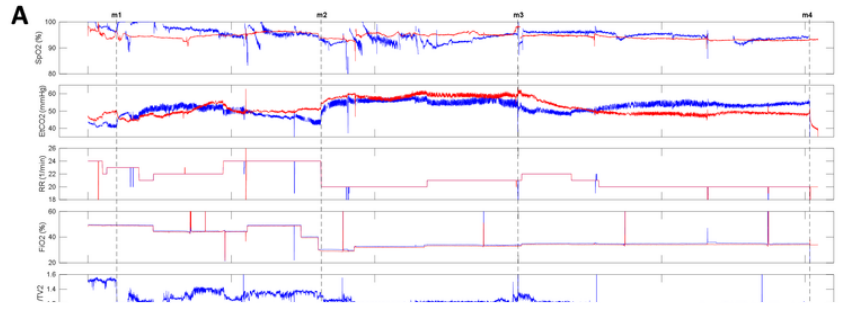

\section{Figure 2}

Time traces for the selected animal experiments. (A-B) Ventilatory parameters over time for experiment (pair) 6. (C) Ventilatory parameters for experiment 3. Blue traces denote object \#1, while red traces denote object \#2 (except TV1/TV2). Markers: m1, changing Ventil flow division knob; m2, respiratory rate reducing; $\mathrm{m} 3$, animal position changing from left side to the right side; $\mathrm{m} 4$, one object exchanging with a $2 \mathrm{~L}$ respiratory bag; $\mathrm{S} 1$, injection of the first $100 \mathrm{ml}$ of saline to pig \#1; p1, ventilatory parameters changes; p2 and p3, the times when a 2-liter respiratory bag was connected instead of pig \#1 and \#2, respectively; s2, injection of the second $100 \mathrm{ml}$ of saline to pig \#1; p4, animal position changing from the right side to the left side; $\mathrm{p} 5$, the \#1 object exchanging with a $2 \mathrm{~L}$ respiratory bag; MV, minute ventilation; TV, tidal volume; FiO2, oxygen fraction in the inhaled gas; SpO2, arterial blood saturation; EtCO2, end-tidal carbondioxde; TV1/TV2, tidal volumes ratio - ventilation ratio; PIP, peak inspiratory pressure; Pplat, plateau pressure; PEEPi, intrinsic positive end-expiratory pressure; $\triangle \mathrm{P}$, driving pressure (Pplat - PEEPi); TVe, expiratory tidal volume, Cst, static lungs compliance (TVe/(Pplat - PEEPi)). 


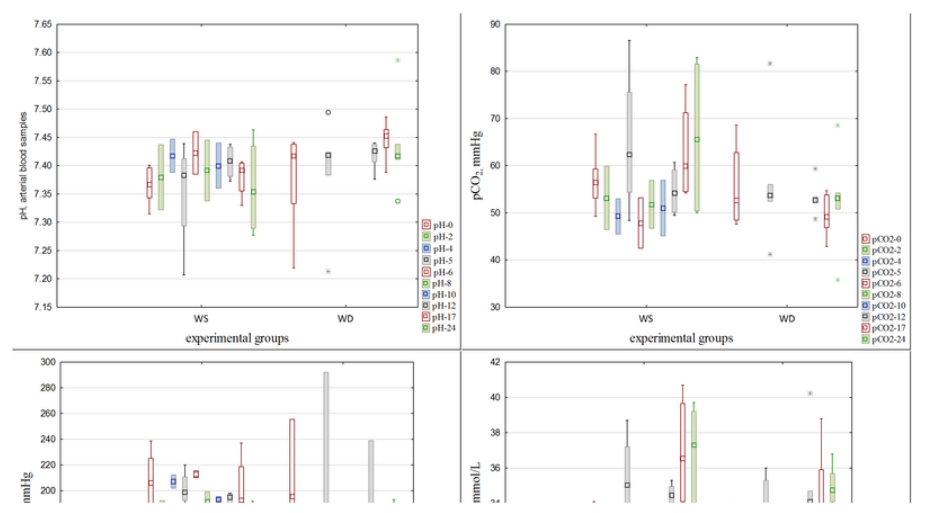

\section{Figure 3}

Results of the repeated-measures ANOVA Friedman test overall parameters for two experimental groups. Circles describe outliers in the interquartile range (IQR) and are obtained by calculating the deviation between the 75th and 25th percentiles. Asterisks describe extreme values. $\mathrm{pH}$, the activity of hydrogen ions; pCO2, carbon dioxide partial pressure; p02, oxygen partial pressure; cHCO3-, bicarbonate concentration; Be(ecf), base excess in the extracellular fluid; $\mathrm{SaO} 2$, oxygen saturation of hemoglobin, lactate, lactate level;

\section{Supplementary Files}

This is a list of supplementary files associated with this preprint. Click to download.

- Zielinskisupplementary.pdf 